\title{
COVID-19 vaccines - the magic bullet?
}

At the time of writing (2 December 2020) there were 51 candidate vaccines for COVID-19 in clinical evaluation. ${ }^{[1]}$ The proviso at the time of writing' is particularly pertinent in a world where COVID-19 vaccine development has been quite astonishingly rapid. Vaccines generally take up to 10 years to get to market, with five stages of development: ${ }^{[2]}$ discovery-research, taking 2 - 5 years; preclinical, taking 2 years; clinical development (with three phases, phase I, taking 1 - 2 years; phase II, taking 2 - 3 years; and phase III, taking 2 - 4 years); regulatory review and approval, taking 1 - 2 years; and finally manufacturing and delivery. Clinical development answers three questions: is it safe? does it activate an immune response? and does it protect against the disease? Manufacturing vaccines requires specialist facilities that are highly regulated and expensive to develop, usually starting following phase II clinical trials to develop the thousands of doses required for phase III trials. COVID-19 vaccines went into human testing in March this year, ${ }^{[2]}$ and the UK approved the Pfizer/BioNTech COVID vaccine for rollout - yes, actually injecting the vaccine into people - on 2 December. Vaccine programmes will start from the week beginning 7 December in the UK, targeting a highly selected group of vulnerable people. ${ }^{[3]}$ This is an astonishing 9 months since the first trials started.

At the time of writing there are three vaccines, including the Pfizer/ BioNTech one, that are just about ready for rollout (I am not including the Russian or Chinese vaccines that are being rolled out, because we have no reliable data on their efficacy and safety - as someone said to me regarding the Russian vaccine when it was announced, 'Stick to the sausages'). Two, including the Pfizer/BioNTech vaccine, are mRNA vaccines. The second of these, the Moderna mRNA-1273, was filed for Emergency Use Authorization with the US Food and Drug Administration on 30 November 2020 on completion of their phase III trial. These two vaccines have reported efficacy in the region of $95 \%$. The third is a vaccine being co-investigated by AstraZeneca and Oxford University (Oxford/AstraZeneca), with trials taking place in South Africa, which reports $70 \%$ efficacy, with a possible increase up to $90 \%$ depending on the dosing schedule. However, questions are being asked about whether these results stand up to scrutiny. ${ }^{[4]}$ At the moment this is equivocal, with methodological issues that include pooling phase III trial data from two separate trials, one in the UK, the other in Brazil, along with a 'glaring mistake' in the way one of the two trials was conducted, in which some UK participants got roughly half of the intended dose of their first shot. Although this led to the happy finding of greater efficacy (maybe!) with this dosing schedule, the dosing error violated the trials protocol, which means that there are reasons to doubt the overall numbers. Simply put, too small a number of people received the half dose rather than the full dose, leading to an underpowered trial because of inadequate sample size. As well as that potential problem, the two separate phase III trials were performed under different protocols; the UK conducted a combined phase II/III trial, while that in Brazil was a pure phase III trial. Both used different placebos. All this potentially leads to some pretty complex statistical number crunching to take these differences into account, and as yet, details of the methodology haven't been published. The results of the UK trial have been published in The Lancet, ${ }^{[5]}$ but the full combined results are still to be submitted to a journal. Another possible confounding factor is that the people in the half-dose group were younger on average than participants as a whole, and vaccines usually work better in younger people. And COVID-19 is particularly severe in those over the age of 60 years. So, it looks as though the efficacy of this vaccine is probably somewhere between $62 \%$ and $90 \%$ - full results still to be announced - which on balance is probably pretty good, and hopefully all the methodological issues will be ironed out as the trials continue.

And now to the nitty-gritty. Will we get a vaccine, any vaccine, here in South Africa and across the rest of the continent any time soon? The first two vaccines, which are likely to be the first to be available in any numbers, need to be stored at $-70^{\circ} \mathrm{C}$, but can then last for a few days in a normal fridge for transportation. Both require two doses, 28 days apart. The Oxford/AstraZeneca vaccine is not an mRNA vaccine and so can be stored in a normal fridge, making cold-chain issues far less of a problem, and also requires two doses. We know that with the best will in the world, cold chains are broken and the logistics around storing and distributing the mRNA vaccines probably make them pretty much unsuitable for our context, so the yet to be finalised and approved Oxford/AstraZeneca is likely to be the first available to us. And then there is the politics - and hasn't so much of this pandemic been about politics! South Africa has apparently missed the first payment of ZAR500 million to secure our place on COVAX, a UN-sponsored global vaccine initiative. ${ }^{[6]}$ This is the first payment required to ensure that we can secure enough doses of whichever vaccine becomes available for $10 \%$ of our population of 56 million to be vaccinated. The Solidarity Fund is now expected to step in and make a payment of ZAR300 million, or 15\% of the total envisaged spend, still requiring a further ZAR4.5 billion. It would seem that ZAR10 billion for our failed state airline takes greater priority, although apparently that too is simply a number at the moment! So, my take on getting a vaccine in South Africa any time soon? I wouldn't rush to book your next flight to Australia on Qantas quite yet.

\section{Bridget Farham \\ Editor \\ ugqirha@iafrica.com}

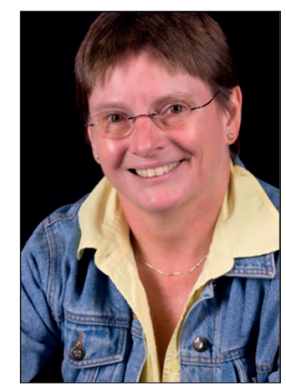

1. World Health Organization. Draft landscape of COVID-19 candidate vaccines. https://www.who.int/ publications $/ \mathrm{m} /$ item/draft-landscape-of-covid-19-candidate-vaccines (accessed 2 December 2020). World Economic Forum. Five charts that tell the story of vaccines today. https://www.weforum.org/ agenda/2020/06/vaccine-development-barriers-coronavirus/ (accessed 2 December 2020).

3. Guardian Online. UK approves Pfizer/BioNTech Covid vaccine for rollout next week. https://www. theguardian.com/society/2020/dec/02/pfizer-biontech-covid-vaccine-wins-licence-for-use-in-the-uk (accessed 2 December 2020)

4. Lawton G. Do Oxford/AstraZeneca covid-19 vaccine results stand up to scrutiny? New Scientist, 27 November 2020. https://www.newscientist.com/article/2261092-do-oxford-astrazeneca-covid-19vaccine-results-stand-up-to-scrutiny/ (accessed 2 December 2020).

5. Ramasamy MN, Minassian AM, Ewer KJ, et al. Safety and immunogenicity of ChAdOxl nCoVt9 vacione 19 vacche admis $32466-1$

6. Cowan K. COVID-19 vaccine: SA missed first payment window to join COVAX, a global vaccine access initiative. News24. https://www.news24.com/news24/southafrica/investigations/exclusive-covid-19vaccine-sa-missed-first-payment-window-to-join-covax-a-global-vaccine-access-initiative-20201203 (accessed 2 December 2020) 